Revista Bioética

\title{
ATUALIZAÇÃO
}

\section{Eutanásia sob a perspectiva da bioética e clínica ampliada}

Rubens Bedrikow

Departamento de Saúde Coletiva, Faculdade de Ciências Médicas, Universidade Estadual de Campinas, Campinas/SP, Brasil.

\section{Resumo}

"Eutanásia" significa causar óbito rápido e indolor ou não o evitar, visando aliviar o sofrimento do paciente quando a morte é entendida como melhor bem ou menor mal. "Clínica ampliada" diz respeito à expansão do objeto de interesse clínico, ocupando-se não apenas da doença, mas também e sobretudo do sujeito singular. O objetivo deste trabalho é analisar a eutanásia a partir da bioética ampliada. Para isso, utilizou-se trecho do romance Anne Prédaille, do escritor francês Henri Troyat, no qual a personagem principal provoca a morte da mãe aplicando dose elevada de morfina. O fragmento mostra a eutanásia como questão de sujeitos com histórias de vida singulares que se inter-relacionam, e não como a passagem asséptica da vida para a morte. Concluiu-se que a bioética deve considerar a história das pessoas envolvidas no processo da eutanásia.

Palavras-chave: Eutanásia. Bioética. Medicina clínica. Medicina na literatura.

\section{Resumen}

\section{La eutanasia desde la perspectiva de la bioética y la clínica ampliada}

"Eutanasia" es hacer que una persona muera rápidamente y sin dolor, o no evitarlo, con el fin de aliviar el sufrimiento, cuando la muerte se entiende como el mejor bien o el menor mal. "Clínica ampliada" se refiere a la expansión del objeto de interés de la clínica, que se ocupa no solo de la enfermedad, sino también y sobre todo del individuo. El objetivo de este trabajo es analizar la eutanasia desde una bioética ampliada. Para ello, se utilizó un extracto de la novela Anne Prédaille del escritor francés Henri Troyat, en la que el personaje principal provoca la muerte de la madre por la aplicación de una alta dosis de morfina. El fragmento muestra la eutanasia como una cuestión de sujetos con historias de vida únicas que se interrelacionan, y no como la transición aséptica de la vida a la muerte. Se llegó a la conclusión de que la bioética debe considerar la historia de la vida de las personas que participan en el proceso de eutanasia.

Palabras clave: Eutanasia. Bioética. Medicina clínica. Medicina en la literatura.

\begin{abstract}
Euthanasia from the perspective of extended bioethics and clinics

"Euthanasia" is the act of intentionally ending a life quickly and painlessly, or omitting to prevent it, to alleviate suffering when death is understood as the greater good or the lesser evil. An "extended clinical approach" refers to the expansion of the object of clinical interest, which is concerned not only with the disease, but also and above all with the individual. This study analyzes euthanasia from the perspective of extended bioethics. To this end, we used an excerpt from the novel Anne Prédaille by French writer Henri Troyat, in which the main character causes the death of her mother, who suffers from a terminal illness, by applying a high dose of morphine. The literary fragment was intended to show euthanasia as a matter of subjects with unique interrelated life stories, and not as the aseptic passage from life to death. We concluded that bioethics must consider the life history of people involved in the process of euthanasia.
\end{abstract}

Keywords: Euthanasia. Bioethics. Clinical medicine. Medicine in literature.

Declaram não haver conflito de interesse. 
A bioética é campo de conhecimento multi e interdisciplinar que estuda a conduta humana nas ciências da vida e nos cuidados em saúde, à luz de valores e princípios morais ${ }^{1,2}$. Interessa-se por ampla gama de eventos ocorridos desde o início até o término da existência humana. Este artigo tem como recorte a terminalidade da vida, mais particularmente a eutanásia.

No Dicionário Oxford de filosofia de Simon Blackburn, esse verbete aparece como ação de causar diretamente a morte rápida e indolor a uma pessoa, ou de não a evitar, num caso em que o agente tem a possibilidade de intervir ${ }^{3}$. Oliveira e Baptista, por sua vez, definem "eutanásia" como a morte provocada por compaixão, sem qualquer interesse próprio, a pedido de paciente com intenso sofrimento físico, portador de doença grave em fase terminal, porém, capaz e consciente no momento do pedido ${ }^{4}$.

Quando se discute o tema surge a questão de sua legalidade na Bélgica e na Holanda desde 2002. Contudo, mesmo nesses países a discussão está longe de se encerrar. Alguns pediatras e grupos de pais reivindicam o mesmo direito para menores de 12 anos, atualmente impedidos de requisitar eutanásia. Outros, por sua vez, criticam a premissa de que a morte seria a única forma de aliviar sofrimento insuportável, pois existem sedativos potentes capazes de alcançar esse objetivo. Para estes, a prática da eutanásia prejudicaria o desenvolvimento dos cuidados paliativos ${ }^{5}$.

O objetivo deste trabalho é discutir a eutanásia sob a perspectiva da bioética ampliada, em analogia à clínica ampliada, isto é, levando em consideração a história de vida, os desejos, afetos, saberes e poderes das pessoas envolvidas no processo. Para tanto, parte-se de trecho do romance Anne Prédaille, do escritor francês Henri Troyat ${ }^{6}$, no qual a filha de uma personagem com doença terminal dá fim ao sofrimento materno, provocando-lhe a morte.

\section{A clínica ampliada}

O adjetivo aposto à palavra "clínica" refere-se à extensão de seu objeto, meios e objetivos. Enquanto a assistência tradicional volta-se para a doença, na clínica ampliada se enfatiza o sujeito e o contexto, sem descuidar da doença. A expressão foi cunhada por Campos $^{7}$, influenciado por Basaglia, Sartre e Gramsci, e diz respeito à clínica do sujeito.

De Basaglia, Campos ${ }^{7}$ aproveitou a valorização da fala do indivíduo adoecido ou com risco de adoecer, sua inclusão na elaboração de seu próprio projeto terapêutico, e a recusa à objetivação e redução da pessoa doente a caso patológico. De Sartre, emprestou o conceito de sujeito responsável por suas decisões na vida, avesso à postura passiva segundo a qual o outro (profissional de saúde) é quem decide, sozinho, a trajetória futura da pessoa doente. Nesse sentido, a clínica ampliada se distancia da tradicional por não admitir a dominação consentida (conceito de Gramsci), isto é, a concordância passiva do paciente em relação ao profissional da saúde, detentor do saber e poder. Assim, a consulta transforma-se em espaço tanto de prática médica em sentido estrito como de pactuação e negociação.

Nesse tipo de clínica há espaço para o imprevisível, para demandas singulares que não podem ser simplesmente encaixadas em doenças. Isso exige ferramentas para além da anamnese tradicional, do exame físico e do raciocínio patofisiológico. É necessário explorar a história de vida dos sujeitos, com escuta menos seletiva, menos dirigida e mais aberta e tolerante com o inesperado.

Também é preciso que outros profissionais que não o médico e outras teorias além da biomedicina contribuam, assim como são necessárias reuniões de equipe, apoio matricial e construção de projetos terapêuticos singulares. A clínica ampliada não objetiva somente prevenir, tratar e curar doenças, não pretende apenas reabilitar e promover a saúde do paciente, mas permitir que a pessoa escolha e não se reduza à doença que porventura a acompanhe. Essa proposta de reformular e ampliar a clínica compõe projeto mais amplo denominado "método da roda" ou "método Paideia", que aposta na cogestão, buscando compreender e interferir em afetos, conhecimento e relações de poder ${ }^{8}$.

\section{Eutanásia no romance Anne Prédaille}

O escritor francês Henri Troyat ${ }^{6}$ publicou Anne Prédaille em 1973, mesmo ano em que a Corte de Leeuwarden, na Holanda, julgou culpada a médica Truus Postma, que, com ajuda do marido clínico-geral, Andries Postma, abreviou a vida da mãe. Vítima de hemorragia cerebral grave, com perda da audição, dificuldade de fala e precisando ser amarrada na cadeira para não cair, suplicou repetidas vezes a sua filha para deixar de viver, sendo finalmente injetada com $200 \mathrm{mg}$ de morfina. Naquela época, eutanásia era proibida na Holanda, e teoricamente a médica seria condenada a 12 anos de prisão. No entanto, a pena foi apenas simbólica $^{9}$. O caso Postma teve grande repercussão na imprensa, e muito provavelmente induziu Troyat a escrever a obra que serviu de base para esta discussão. 
Henri Troyat é pseudônimo de Lev Aslanovitch Tarrassoff, que nasceu em Moscou em 1911 e emigrou para a França em razão da Revolução Bolchevique. Foi membro da Academia Francesa de Letras e escreveu mais de 100 obras. Faleceu em 2007, aos 95 anos de idade. É possível que também a convivência com sua sogra em fase terminal o tenha influenciado de alguma forma na escrita de Anne Prédaille ${ }^{6,10}$.

A protagonista do romance é uma mulher separada que mora no apartamento dos pais, Pierre e Emilienne (Mily). Cabe a ela cuidar da mãe, acometida de câncer terminal. O sofrimento é diariamente combatido com doses de morfina:

Lágrimas escorreram de suas pálpebras enrugadas:

- Estou com dor, Anne... Não aguento mais...

Esta queixa miserável atingiu Anne na carne. Ela não queria mais escutar isso. Nunca mais!

- Onde você tem dor, mamãe?

Emilienne não respondeu e virou a cabeça sobre o travesseiro, se lamuriando. Um monstro devorava seu interior. Chega! Chega!... Decidida, Anne se aproximou da mesa onde estavam os remédios. Suas mãos tremiam. "É agora que eu devo agir. Se eu demorar mais, eu não conseguirei mais. Ela está sofrendo muito. Mas o que eu Ihe darei em troca desse sofrimento? $O$ que sei da noite onde eu a envio? Meu Deus, ajude-me!... Não, não Deus!... Eu só... Rápido!" Ela pegou uma ampola de morfina e serrou sua ponta. Seus dedos não tinham mais força. A ampola lhe escapou. Uma parte de seu conteúdo se espalhou pelo chão. Ela aspirou o que restava. $O$ líquido subia na seringa. Uma água de morte, clara, transparente. Mais uma ampola. A quebra certa. A agulha bombeava o veneno. $O$ êmbolo forçava no tubo. A mão de Anne se contraía. Ela ia desistir. Uma outra ampola. E uma outra ainda... O dr. Maurin havia dito para não ultrapassar a dose. Desta vez a seringa estava cheia. O êmbolo quase inteiramente para fora. Nenhuma bolha de ar. Tudo estava pronto. Nem algodão nem álcool. "Perdão, mamãe!" Esta exclamação silenciosa explodiu na cabeça de Anne e ela se viu a ponto de desmaiar. Esvaziar a seringa na pia, esquecer tudo. Não. Num esforço de vontade, ela se inclinou sobre a cama. "Vamos! Agora... agora..." Ela murmurava. Ela pegou o braço de Emilienne, o levantou com cuidado. Ela manipulava um esqueleto. Tão seco, tão leve. Sob o seu olhar, essa pele de marfim, murcha e doce, da qual cada centímetro quadrado the era mais caro que sua própria pele. Ela plantou a agulha. A doente não estremeceu. Foi Anne que sentiu a picada. No mais profundo de seu coração. Ela mordeu os lábios para não gritar. O êmbolo da seringa expulsou o líquido. Mas tão lentamente! O nível não terminava de descer. Ela ia ficar louca. Ainda algumas gotas. Anne retirou a agulha com um gesto seco. Suas pernas dobravam. Ela arrumou a cabeça de Mily sobre o travesseiro, bem no centro.

- Você me deu minha injeção, sussurrou Emilienne sem abrir novamente os olhos. Obrigada, minha querida...

Anne se dominou e disse com uma voz débil:

- Agora, Mily, tudo ficará bem. É preciso dormir.

- Bom... Então, é isso... Você quer que eu durma... Mas me dê sua mão... Segure firme.

Anne se acomodou, arrasada, na poltrona, na cabeceira da cama, e pegou na sua mão a mão fina que se rendia. Nesta altura Mily sorria, Ihe parecia, com malícia. Como se ela houvesse compreendido tudo, como se ela aprovasse tudo.

\section{(...)}

Despertada bruscamente, Anne se ergueu parcialmente sobre os travesseiros. Havia duas semanas que ela era retirada de seu sono, toda noite, à mesma hora, pelo mesmo pensamento obsessivo. Pela centésima vez, ela espetava o braço de Mily. A agulha na pele. A descida interminável do líquido na seringa. Amar um ser é tentar o impossivel para lhe evitar a dor. Abandonada a se encarregar ela mesma de uma responsabilidade atroz. Agora o sofrimento de Mily estava terminado, o seu começava. Não físico, mas moral. E não existia nenhuma droga para lhe curar. Se ela tivesse tido convicções religiosas, talvez ela tivesse recuado. Doce covardia dos crentes que, em qualquer ocasião, recorrem a uma regra para se pouparem o esforço da decisão e a tortura do remorso ${ }^{11}$.

\section{Eutanásia sob a perspectiva da bioética tradicional}

A morte de Mily, ao lado da filha, em casa e não no hospital, corresponde ao que Berlinguer ${ }^{12}$ considerou "morrer bem". Do ponto de vista etimológico, eutanásia corresponde a boa morte: "eu", do grego, equivale a "bom", "verdadeiro", enquanto "thanatos" significa "morte". 
Anne sofre porque desobedeceu a uma das normas básicas da moral: "não matar" ${ }^{13}$. Praticou o que se conhece como "eutanásia ativa", isto é, agiu deliberadamente para provocar óbito com intenção de aliviar o sofrimento, pois julgou ser a morte o melhor bem, ou o menor mal, para sua mãe ${ }^{14}$. Seu martírio é, sem dúvida, moralista, uma vez que sob essa ótica não poderia abreviar a vida de Mily e colocar suas escolhas individuais acima de um bem maior e geral, não passível de questionamento ${ }^{13,15}$.

Noções como dever, obrigação e princípios de conduta, presentes na moral kantiana, é que produziram, ao menos em parte, sentimentos de incerteza e remorso em Anne. A norma moral desrespeitada por ela ao provocar a morte da mãe faz parte de um sistema de valores considerados corretos pela sociedade a que pertence. De acordo com Segre ${ }^{16}$, as gerações precedentes transferem para a atual uma moral carregada de obrigações.

$O$ ato de Anne Prédaille pode ser analisado sob os princípios da bioética, presentes no Relatório Belmont ${ }^{17}$ e no livro Principles of biomedical ethics, de Beauchamp e Childress ${ }^{18}$. Sua atitude é considerada eticamente correta, haja vista que se mostrou coerente diante do conflito interno, decidindo de forma ativa e autônoma pela morte de sua mãe ${ }^{14}$. Segundo Segre ${ }^{16}$, a eticidade na ação de Anne não está na sua obediência a regras, códigos ou princípios, mas na sua capacidade de reconhecer o dilema entre a norma moral e o benefício de encerrar o sofrimento da mãe, a quem se dedicara durante a evolução da doença incurável.

De acordo com Emanuel ${ }^{19}$, tanto a autonomia como a beneficência constituem argumentos favoráveis à eutanásia. 0 princípio da beneficência precede o da autonomia e já estava presente no voto profissional dos médicos - também conhecido como juramento de Hipócrates, não obstante não ter sido escrito por ele nem mesmo ter feito parte dos ensinamentos das escolas de Cós ou de Cnido; provavelmente é anterior a Hipócrates, de origem pitagórica ${ }^{20,21}$. Por intermédio desse voto, o médico jura aplicar seus conhecimentos para o bem do doente segundo seu poder e entendimento, nunca para causar dano ou mal a alguém. Em toda casa entrará para o bem dos doentes, mantendo-se longe de todo dano voluntário.

O Código de Ética Médica brasileiro ${ }^{22}$ abarca em seus princípios fundamentais a beneficência, a não maleficência e a autonomia. Sobre a beneficência, evidencia que o alvo da atenção médica é a saúde do ser humano, em benefício do qual o profissional deve agir e usar o melhor do conhecimento científico. A não maleficência veta ao médico utilizar seus conhecimentos para causar sofrimento físico ou moral. Já a autonomia está garantida tanto para o médico, desobrigado de exercer a profissão se isso contrariar os ditames de sua consciência, como para o doente, que poderá fazer escolhas terapêuticas desde que adequadas ao caso e cientificamente reconhecidas.

Se, por um lado, Anne apoiou-se na sua capacidade de decisão reflexiva individual, na possibilidade de optar para, como cuidadora, exercer sua autonomia, por outro, agiu de forma paternalista, fundamentada essencialmente na beneficência, independentemente do consentimento explícito da mãe e da violação de uma regra moral compartilhada por ambas ${ }^{23}$. Apesar desses traços paternalistas, o trecho transcrito do romance de Troyat ${ }^{6}$ deixa igualmente a impressão de que a cumplicidade que uniu as personagens durante os meses de doença fez com que a decisão não fosse apenas da filha. Quando Mily sorri depois de receber a morfina, Anne percebe que a mãe aprovara sua atitude.

Segundo Segre ${ }^{16}$, o ser humano é culturalmente paternalista, e a beneficência precede a autonomia. Isso significa que o desejo de acabar com o sofrimento da mãe é anterior ao princípio ético que justifica o ato de Anne. Para esse autor, diferenças puramente acadêmicas, dependentes de interpretações, separam o não fazer mal do fazer o bem. Por esse motivo, Segre ${ }^{16}$ discorda da criminalização da eutanásia ativa, enquanto a passiva (a pedido expresso do doente terminal) é considerada não maleficência.

A bioética principialista, contudo, mostra-se insuficiente para entender a eutanásia praticada pela personagem Anne Prédaille como questão de sujeitos com histórias singulares que se inter-relacionam, e não apenas como passagem asséptica da vida para a morte. Tal constatação soma-se a diversas críticas que o principialismo vem recebendo, sobretudo no que diz respeito aos limites de sua aplicabilidade, não se constituindo em teoria de caráter universal compatível com a diversidade moral das sociedades contemporâneas ${ }^{24}$.

\section{Eutanásia sob a perspectiva da bioética ampliada}

Ampliar a bioética da forma proposta por Campos $^{7}$ para a clínica corresponde a considerar a eutanásia não como entidade separada 
conceitualmente dos sujeitos envolvidos no processo, mas como acontecimento singular, determinado pela história e pelos recursos de cada indivíduo, família ou grupo social. Para além do fim intencional da vida biológica, ainda que ético, a eutanásia consiste em evento complexo que envolve relações de poder, saberes, sentimentos, afetos, crenças religiosas e valores culturais tanto individuais quanto da sociedade na qual os sujeitos se inserem.

Portanto, a bioética ampliada não se limita a reconhecer duas modalidades de eutanásia, passiva e ativa. Interessa-se também por outros temas e convida o doente e demais sujeitos a participar das decisões sobre cuidado e processo de morte, sem evitar os desafios emocionais, sociais, culturais e econômicos envolvidos nessa dinâmica.

Ao abordar a eutanásia sob a ótica da bioética ampliada, acolhe-se e valoriza-se aquilo que é amiúde desvalorizado pelo entorno social, principalmente no meio científico: as falas dessas pessoas. Devolve-se ao sujeito a autonomia, sua capacidade de gerenciar a própria vida e morte. Abre-se espaço para negociação, retirando enfermos e familiares da condição de dominados por consentimento. Portanto, essa perspectiva se aproxima do pensamento de Sartre ao evitar que o paciente seja apenas espectador, oferendo-lhe a possibilidade de pensar e decidir, de fazer escolhas conjuntas, ainda que isso lhe traga certa angústia, mormente se infringir regras morais.

No caso de Anne Prédaille, ampliar a bioética significaria escutar sua história, particularmente ao lado da mãe, valorizando seu olhar singular para o sofrimento e a morte, abrindo espaço para seus medos e dilemas morais, sem se restringir aos desafios biológicos do fim da vida nem se esquivar da complexidade do processo de adoecer e morrer. Para Anne, pôr fim à vida de Mily era encerrar uma íntima relação entre mãe e filha, estreitada com a chegada da doença maligna e incurável, responsável por atroz sofrimento físico e emocional, implicando a necessidade de construir um futuro sem a mãe.

Da escuta atenta da narrativa livre, em conversas entre profissionais de saúde, enfermos e/ou familiares poderiam emergir temas relevantes. As histórias dos adoecidos rompem a centralidade do modelo biomédico no discurso da doença e permitem aos sujeitos dar sentido à vida e ao sofrimento, diminuindo assim sua dependência da biomedicina e aumentando seu protagonismo e autonomia ${ }^{25}$. É sob essa ótica, ampliada pelo conhecimento anterior de elementos da história de Anne, que sua atitude pode ser entendida e analisada do ponto de vista ético.

A clínica e a bioética ampliadas avançam para além do que a razão e a consciência permitem enxergar, incluindo em suas práticas conceitos da teoria psicanalítica ${ }^{26}$. Em outras palavras, consideram os conflitos pessoais presentes no inconsciente de cada indivíduo como codeterminantes de suas ações.

Troyat deixa transparecer no seu texto elementos do inconsciente de Anne que podem ser considerados no momento de abordá-la, tanto do ponto de vista clínico como ético: Esta queixa miserável atingiu Anne na carne (...) Foi Anne que sentiu a picada (...) ela era retirada de seu sono, toda noite, à mesma hora, pelo mesmo pensamento obsessivo ${ }^{11}$. Tais trechos expressam grande sofrimento da personagem, assim como a persistência de um pensamento forte o suficiente para acordá-la todas as noites. São esses elementos subliminares que a abordagem ampliada evita desprezar.

A relação das pessoas com a morte mudou ao longo da história. Até o final da Idade Moderna, vida e morte coexistiam no âmbito doméstico e familiar, mas a partir do século XIX os óbitos passaram a acontecer nos hospitais, entregues à racionalidade fria dos profissionais da saúde ${ }^{27}$. A bioética ampliada, que valoriza a narrativa dos pacientes, revela-se potente para lidar com questões atuais relacionadas à terminalidade da vida, como eutanásia, cuidados paliativos e diretivas antecipadas de vontade.

\section{Considerações finais}

A análise da eutanásia a partir do fragmento da obra de Troyat ${ }^{6}$ revela que esse procedimento é complexo e singular, não envolvendo somente a pessoa que morre, mas também familiares, amigos e cuidadores. Além disso, não se limita ao momento da morte propriamente dito, pois abarca diferentes aspectos dos indivíduos, antes e depois do funesto evento. Portanto, da mesma forma que a clínica ampliada utiliza a história dos sujeitos para elaborar projetos terapêuticos singulares, que lhes permitam continuar fazendo escolhas e gerenciando a própria vida mesmo acometidos por doença, a bioética ampliada considera a narrativa das pessoas envolvidas no processo da eutanásia e mostra-se mais coerente com a complexidade da existência humana. 


\section{Referências}

1. Oliveira RA, Cohen C, Gobbetti GJ. Ética médica e bioética na Faculdade de Medicina da Universidade de São Paulo: uma trajetória. In: Cohen C, Oliveira RA, editores. Bioética, direito e medicina. Barueri: Manole; 2020. p. xix-xxix.

2. Leutério AP, Castelhano APMSF, Cohen C, Almeida JPS, Sarmento JS, Callegari LA et al. Noções preliminares: origem, evolução e conceito de bioética. In: Cohen C, Oliveira RA, editores. Op. cit. p. 2-10.

3. Blackburn S. Dicionário Oxford de filosofia. Rio de Janeiro: Jorge Zahar; 1997. Eutanásia; p. 132.

4. Oliveira RA, Baptista PG. Terminalidade de vida: dignidade da pessoa humana. In: Cohen C, Oliveira RA, editores. Op. cit. p. 782-98. p. 787-8.

5. Brouwer M, Kaczor C, Battin MP, Maeckelberghe E, Lantos JD, Verhagen E. Should pediatric euthanasia be legalized? Pediatrics [Internet]. 2018 [acesso 22 jul 2020];141(2):e20171343. DOI: 10.1542/peds.2017-1343

6. Troyat H. Anne Prédaille. Paris: Flammarion; 1973.

7. Campos GWS. A clínica do sujeito: por uma clínica reformulada e ampliada. In: Campos GWS. Saúde paidéia [Internet]. São Paulo: Hucitec; 2003 [acesso 10 mar 2020]. p. 51-67. Disponível: https://bit.ly/2OZWm9v

8. Campos GWS. Memórias de um médico sanitarista que virou professor enquanto escrevia sobre... São Paulo: Hucitec; 2007.

9. Sheldon T. Andries Postma. BMJ [Internet]. 2007 [acesso 22 jul 2020];334(7588):320. DOI: $10.1136 / \mathrm{bmj} .39111 .520486$.FA

10. Troyat H. Un si long chemin. Paris: Stock; 1987.

11. Troyat H. Op. cit. p. 60-2. Tradução livre.

12. Berlinguer G. Questões de vida (ética, ciência, saúde). Salvador: APCE; 1993.

13. Cohen C, Segre M. Definição de valores, moral, eticidade e ética. In: Segre M, Cohen C, organizadores. Bioética. 2a ed. São Paulo: Edusp; 1999. p. 23-9.

14. Blackburn S. Op. cit.

15. Durant W. História da filosofia: vida e idéias dos grandes filósofos. São Paulo: Companhia Editora Nacional; 1951.

16. Segre M. Considerações críticas sobre os princípios da bioética. In: Segre M, Cohen C, organizadores. Op. cit. p. 175-80.

17. National Commission for the Protection of Human Subjects of Biomedical and Behavioral Research. The Belmont report: ethical principles and guidelines for the protection of human subjects of research [Internet]. Washington: DHEW Publications; 1978 [acesso 2 ago 2020]. Disponível: http://bit.ly/2uyHU0Q

18. Beauchamp TL, Childress JF. Principles of bioemedical ethics. 4a ed. Nova York: Oxford; 1994.

19. Emanuel EJ. Bioética na prática médica. In: Goldman L, Ausiello D. Cecil: tratado de medicina interna. 22a ed. Rio de Janeiro: Elsevier; 2005. p. 5-11.

20. Hippocrates. The physician's oath. In: Carmichael AG, Ratzan RM. Medicine: a treasury of art and literature. Nova York: Beaux Arts; 1991. p. 35-6.

21. Lyons AS, Petrucelli J. Medicine: an illustrated history. Nova York: Harry N. Abrams; 1987.

22. Conselho Federal de Medicina. Código de ética médica: Resolução CFM no 2.217, de 27 de setembro de 2018 [Internet]. Brasília: CFM; 2019 [acesso 3 fev 2020]. Disponível: https://bit.ly/30BwG9x

23. Cohen C, Marcolino JÁM. Relação médico-paciente. In: Segre M, Cohen C, organizadores. Op. cit. p. 51-62.

24. Figueiredo AM. Bioética: crítica ao principialismo, Constituição brasileira e princípio da dignidade humana. Rev. bioét. (Impr.) [Internet]. 2018 [acesso 7 jul 2020];26(4):494-505. p. 498. DOI: $10.1590 / 1983-80422018264267$

25. Bedrikow R. A clínica e as políticas públicas de saúde para a atenção básica no Brasil [tese] [Internet]. Campinas: Universidade Estadual de Campinas; 2013 [acesso 14 jan 2020]. Disponível: https://bit.ly/30C7ONN

26. Canesqui AM. Estudos antropológicos sobre os adoecidos crônicos. In: Canesqui AM, organizadora. Olhares socioantropológicos sobre os adoecidos crônicos. São Paulo: Hucitec; 2007. p. 19-51.

27. Silva EQ. Ideário da morte no Ocidente: a bioética em uma perspectiva antropológica crítica. Rev. bioét. (Impr.) [Internet]. 2019 [acesso 7 jul 2020];27(1):38-45. DOI: 10.1590/1983-80422019271284

\section{Correspondência}

Universidade Estadual de Campinas. Rua Tessália Vieira de Camargo, 126, Barão Geraldo CEP 13083-887. Campinas/SP, Brasil.

Rubens Bedrikow - Doutor - bedrikow@unicamp.br

(iD) $0000-0003-1405-3122$ 